\title{
THE
}

UNIVERSITY

University of Rhode Island

OF RHODE ISLAND

DigitalCommons@URI

Writing and Rhetoric Faculty Publications

Writing and Rhetoric

2016

\section{Why rhetoric matters for ecology}

Caroline Gottschalk Druschke

University of Rhode Island, cdruschke@wisc.edu

Bridie McGreavy

Follow this and additional works at: https://digitalcommons.uri.edu/writing_facpubs

Terms of Use

All rights reserved under copyright.

\section{Citation/Publisher Attribution}

Gottschalk Druschke, C., \& McGreavy, B. (2016). Why rhetoric matters for ecology. Front Ecol Environ, 14(1), 46-52. doi: $10.1002 / 16-0113.1$

Available at: https://doi.org/10.1002/16-0113.1

This Article is brought to you for free and open access by the Writing and Rhetoric at DigitalCommons@URI. It has been accepted for inclusion in Writing and Rhetoric Faculty Publications by an authorized administrator of DigitalCommons@URI. For more information, please contact digitalcommons-group@uri.edu. 


\title{
Why rhetoric matters for ecology
}

\author{
Caroline Gottschalk Druschke ${ }^{1,2 *}$ and Bridie McGreavy ${ }^{3}$
}

Increasingly, scientists and funding agencies such as the US National Science Foundation are recognizing the need for better science communication and more effective broader impacts activities. Compelled to make research more relevant to public stakeholders and policy makers, researchers look for ways to gain the necessary skillset to move their science from the field and laboratory into public forums. We suggest that the ancient discipline of rhetoric provides a useful - and underutilized - path forward. Building from the fundamental connections between ecology and rhetoric and drawing from practical examples at the intersection of these two fields, we demonstrate how rhetoric can inform training in science communication for better academic writing and broader impacts, and can promote interdisciplinary and cross-institutional collaborations that support sustainability science. Integrating rhetoric and ecology helps to address complex and pressing sustainability problems through improved understanding, cooperation, and science and policy actions.

Front Ecol Environ 2016; 14(1): 46-52, doi:10.1002/16-0113.1

$\mathrm{R}^{\mathrm{h}}$ hetoric suffers from a bad reputation. In the USA, media commentaries and political speeches often criticize "mere rhetoric", urging the policy maker or cultural commentator in question to add substance and truth in place of "empty rhetoric". Whenever the two of us teach rhetoric to new groups of natural science and interdisciplinary students, we ask for their impressions of the term. Sometimes a student who participated in an ancient history course can summon Aristotle's definition of rhetoric as the ability "to see the available means of persuasion in each case" (Aristotle 1991). But most often we hear students (and some colleagues) discredit rhetoric as mere "spin": a way to package, sell, and profit from an argument that simply is not true.

\section{In a nutshell:}

- Rhetoric is the academic discipline devoted to the persuasive power of language, including argument, public discourse, and civic engagement. It seeks to understand how people interact with one another and their environments, and how human communities form

- Rhetoric and ecology offer complementary perspectives; both disciplines emerged from a search for knowledge about the world and how it works, and each takes a systems-based approach to human and community interactions

- Rhetoric's focus on the capacity of language to persuade audiences, connect individuals, and affect the biophysical world can strengthen academic writing and broader impacts activities, as well as promoting collaboration that improves sustainability research and policy

${ }^{1}$ Department of Writing and Rhetoric, University of Rhode Island, Kingston, RI; ${ }^{2}$ Department of Natural Resources Science, University of Rhode Island, Kingston, RI *(cgd@uri.edu); ${ }^{3}$ Department of Communication and Journalism, University of Maine, Orono, ME
Although a substantial body of research in rhetoric focuses on persuasion, rhetoric is more broadly about the ways humans communicate with one another and how communication can shape human understanding of and decision making about ecosystems. As such, rhetoric is "something like the condition of our existence" (Bender and Wellbery 1990): the way we make sense of each other and our world.

This may be a frustratingly broad definition of rhetoric, but its inherent flexibility and diversity are its greatest strengths. Rhetoric is multifaceted, featuring multiple dimensions that include the strategic (persuading audiences), relational (connecting individuals), and material (affecting and being affected by the biophysical world). The multidimensional examples we offer here reflect Scott's (1973) suggestion "that people generally have a sense of rhetoric" that "is rooted in experience". Any time we pay attention to the consequences of our language choices for policy, practice, or shifts in perspectives - or we thoughtfully and practically use language to craft manuscripts, ask for funding, or foster collaborations with students and communities - we are engaging in the study and practice of rhetoric. The key is to begin paying more critical and deliberate attention to the effect of rhetoric in scientific research and outreach.

As we discuss below, even an introductory understanding of rhetoric and the tools it provides can have a positive impact on ecological science by: (1) improving science communication training to refine academic writing and broader impacts activities, and (2) advancing interdisciplinary collaboration to support social-ecological research and sustainability science efforts. We highlight an array of practical examples that demonstrate these impacts to encourage more ecologists to think creatively about how an increased attention to language can enhance their work. 


\section{The current model of science communication training}

The US National Science Foundation's (NSF's) mandate that their graduate trainees be prepared "to identify and explain the potential benefits and broader impacts of their research discoveries to a range of stakeholders, including policy makers and the general public" (NSF 2015) attests to a growing commitment to improving science communication, as first suggested in Frontiers a decade ago (Silver 2003; Barker 2006). Programs have emerged around the country to train science faculty and graduate students to be more effective communicators (Kuehne et al. 2014). These programs come in response to a desire among ecologists and other scientists for training in crafting simple and engaging messages (Silver 2003).

NSF's 2012 "Science: Becoming the Messenger" series of national workshops offers a case in point. These workshops trained attendees to use social media for drawing attention to their research, and taught strategies for focusing on key points, including the use of message boxes, which are diagrams that help organize messages into main points (Galindo 2013). We have since adopted many of these approaches in our teaching. But the NSF training was founded on the implicit assumption that communication is something to consider at the end of the research process, and the workshops relied on a transmission model featuring the one-way flow of information from scientists to public audiences. Presenters focused strictly on rhetoric's strategic dimensions, encouraging attendees to tweet streamlined messages about their research, take charge of media interviews, and become "science ninjas", capable of stealthily forcing the general public to care about their science. In our view, although strategic communication is important, communicating relevant science to broad public audiences in consequential ways warrants a richer view of communication informed by rhetoric's strategic, relational, and material dimensions.

\section{Moving from a deficit model to a contextual model of science communication}

Aristotle sought to persuade audiences, but his was not a linear model of transmission. Instead, he searched for common ideas that would connect speakers to audiences through points of shared identification. Gross (1994) grounded this nuanced perspective in the distinction between deficit and contextual models of communication. A deficit model assumes a passive and trusting public, and imagines communication flowing one way - from scientific expert to lay public. In contrast, a contextual model involves interaction and two-way communication, emphasizing the importance of building trust and offering scientific information relevant to particular public audiences.
A contextual view of communication recognizes that audience members are not "empty vessels" (Barker 2006); instead, audiences approach topics from unique standpoints. Successful communication starts with recognizing and valuing where audiences are coming from, and then working to incorporate those perspectives. This iterative, context-dependent view can inform writing practices that connect with particular academic audiences and funding agencies (Druschke 2014) and also enhance the deliberate design (Shirk et al. 2012) and assessment (Skrip 2015) of broader impacts activities.

This rhetorical approach to science communication can serve as the basis for short lessons about rhetoric and the value of writing and speaking with specific audiences in mind. For example, an annual lecture to first-year students in the Masters of Environmental Science and Management (MESM) program at the University of Rhode Island (URI) focuses on the importance of rhetoric as students begin to consider the audiences for, and consequences of, their capstone papers. Students talk through an uncomfortable and humorous set of exercises where they explain a concept like the National Collegiate Athletic Association (NCAA) basketball tournament to a member of the class with no knowledge of basketball and then role-play the different ways they would describe their research to professors, grandparents, and potential community partners. These sorts of improvisational techniques, similar to those taught by faculty at the Alan Alda Center for Communicating Science at Stony Brook University in New York State, offer students the chance to engage in playful activities that encourage experimentation and engagement with audiences, allowing students to consider each particular audience's interests and needs.

\section{Emphasizing the rhetorical situation for writing and engagement}

This contextual view is also known as the rhetorical situation - a systems approach to language that includes the task and facts at hand, type of audience, credibility of the speaker, potential consequences of any speech, medium, genre, and style (Bitzer 1992) - and is central to rhetoric. It can ground science communication training by helping to answer questions of "whether, when, and how" ecologists engage in public outreach activities (Pace et al. 2010). Engagements can be guided by Cicero's five canons of rhetoric, which prompt science communicators to remember what they want to say, arrange content in compelling ways, be creative and inventive through narrative, practice the art of delivery, and adopt a style that fits their situation and audience (Cicero 1968). By improving the delivery of scientific information and the audience's capacity to relate to, or in rhetorical terms identify with (Burke 1969), that information, rhetoric can be used to improve theses and dissertations, competitive grant proposals and fellowship applications, and documents for public 


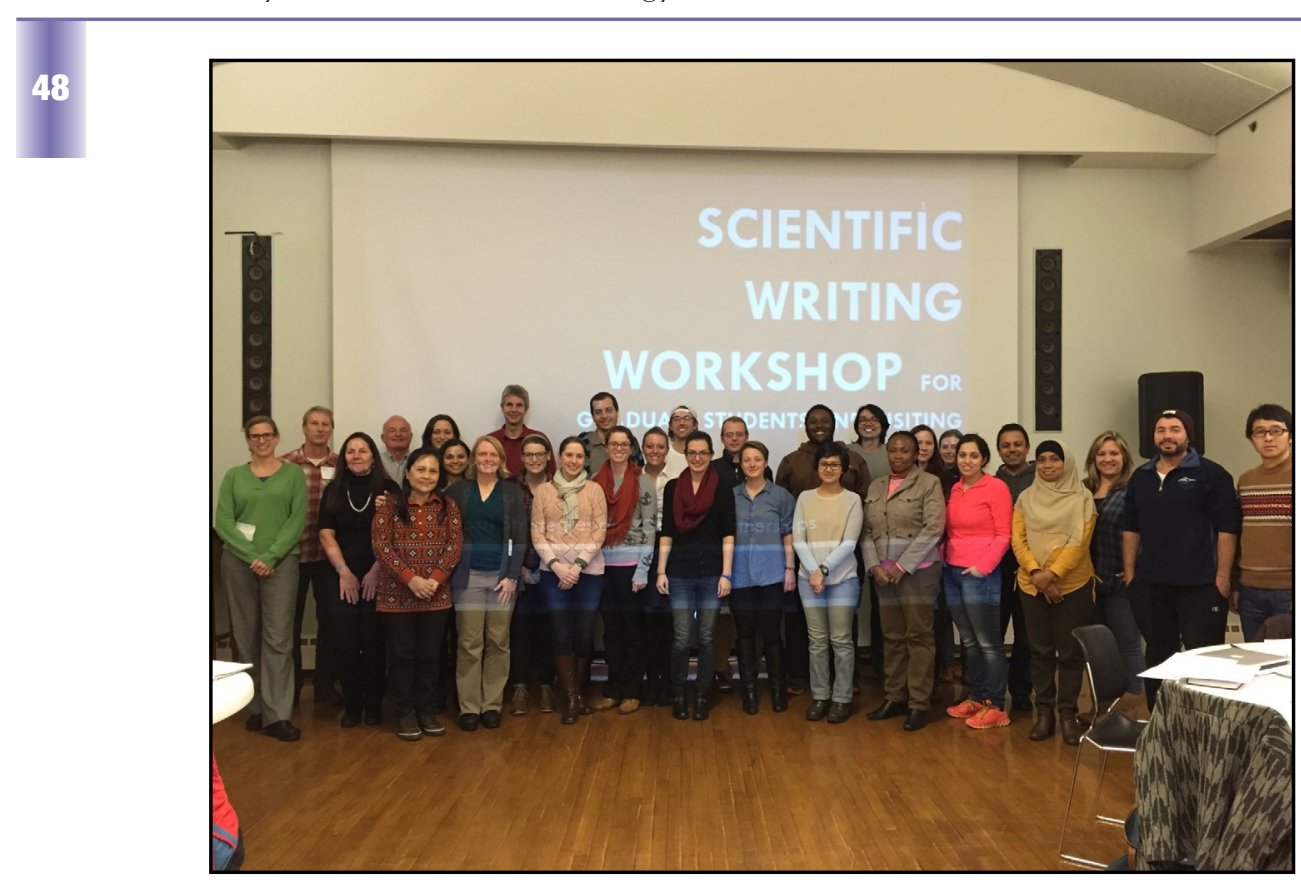

Figure 1. Faculty from the College of the Environment and Life Sciences at the University of Rhode Island teach full-day scientific writing workshops - offered to visiting scholars and graduate students - focused on rhetorical concepts such as audience awareness and peer review.

audiences. It can also contribute to students' critical understandings of scientific concepts (Wallace et al. 2004; Gigante 2015).

This rhetorical approach can improve the teaching of writing in important ways. At URI, for example, a NSF Innovations in Graduate Education award funds an initiative called SciWrite, which includes a graduate and faculty fellowship program in rhetoric and science writing, a Graduate Science Writing Center, and a forthcoming environmental communication track in the MESM program. These initiatives supplement a transmission model of science communication with a rhetorical perspective that stresses context, identification, situation, and consequence through the addition of rhetorically focused required courses such as "Public Engagement with Science" and "Graduate Writing in the Life Sciences". This rhetorical perspective - with its emphasis on creating a habit of writing through engagement in activities across multiple genres, with frequent review and revision - also infuses full-day workshops on scientific manuscript and proposal writing in URI's College of the Environment and Life Sciences (Figure 1).

A focus on the rhetorical situation moves students and faculty away from thinking about writing strictly in terms of grammar and spelling, and toward a view of communication as a powerful way of getting things done in the world - a move that affects much more than writing. This view extends beyond mechanics and sentence structure, and considers how - through language - communities of researchers, students, and members of the public form, adapt, and make shared meaning in particular contexts.

Rhetoric can have a positive impact on a variety of courses throughout scholarly disciplines (Fahnestock 2013). For instance, at URI, this attention to the situated power of language to get things done in the world by connecting individuals with seemingly competing perspectives underlies undergraduate and graduate courses in life-science writing, public engagement with science, and social and ecological aspects of river restoration. In those courses, students regularly write academic papers, proposals, and public documents, as well as design, implement, and critique broader impacts activities meant to engage targeted segments of the population in their research. In recent semesters, URI students conducted rhetorically informed projects that included (1) guiding disadvantaged middle-school students in the city of Providence, Rhode Island through an interactive, bilingual activity at the local library that focused on the causes and possible action steps related to climate change and specifically to sea-level rise; (2) using social media to return thesis results about aquaculture tourism to shellfish growers that participated in the study; and (3) speaking before a town council to request funding for a building to house a fishing cooperative.

\section{Promoting shared meaning and identification}

Connection and collaboration are key areas of attention for rhetorical training, as rhetoric-based initiatives work to promote shared meaning and identification between speakers or writers and audiences. The University of Maine (UMaine) utilized this capacity in its Sustainability Solutions Initiative, a statewide network of sustainability science teams, including more than 100 faculty hailing from over 20 disciplines across the social and biophysical sciences, representing 11 institutions of higher education, and funded by a $\$ 20$ million NSF grant in 2009 (Figure 2; Whitmer et al. 2010; Hart et al. 2015). For that project, collaborators relied on rhetoric to prepare team members for a series of Maine Public Broadcasting documentaries about the teams' science, developing science communication workshops informed by rhetorical theory that helped teams develop and refine messages that audiences could identify with. Workshops built from existing NSF and Communication Partnership for Science and the Sea (COMPASS) models, emphasizing the importance of framing science and the use of techniques, such as 
message boxes, to make messages very clear and accessible for audiences.

These adapted workshop models, which brought rhetoric to the fore, promoted shared meaning and identification with team science between researchers, collaborators, and members of the public (Burke 1969). This subtle but important shift allowed scientists to think beyond information transmission and toward context (Barker 2006). This change was not always comfortable for participants, but the search for Aristotle's "available means of persuasion" helped participants engage communication in a new way. As one participant described, "I learned how to make the knowledge I'm generating most relevant to people." Workshops informed by rhetoric can help people pay attention to context and develop approaches that allow participants to craft "words that work" and that also respect and connect with audiences' understanding and values.

This emphasis on identification and on the ways in which meanings change and differ across contexts can inform broader impacts activities beyond the public lecture. In work with the US National Park Service, Druschke uses rhetoric to train natural science under-

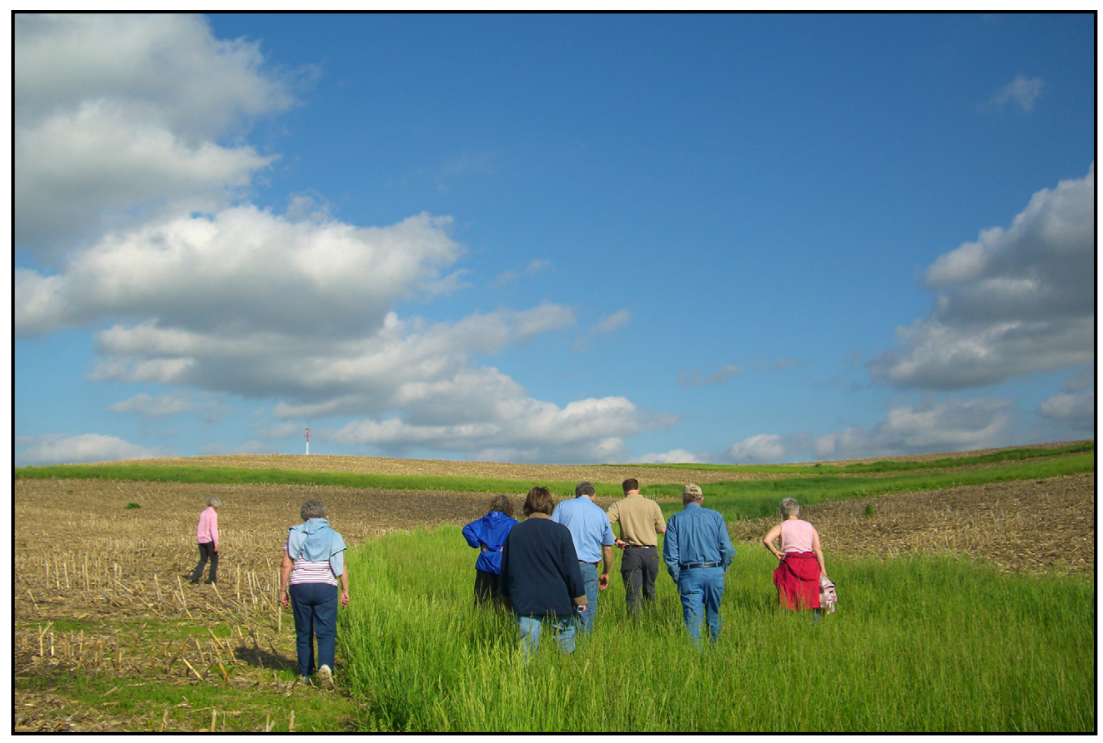

Figure 3. Female agricultural landowners and male conservation staff explore conservation tillage and grassed waterways at a women-centered field day related to best management practices in Iowa's Clear Creek watershed. The event was designed in response to concerns that women were not comfortable communicating with staff in traditionally male-dominated field days. graduate and graduate students in the design of public outreach materials - including resource briefs, researcher profiles, photo stories, interactive maps, and curricular materials - to communicate complex coastal processes in ways that are targeted at the particular information needs, concerns, and interests of park staff and visitors. In another partnership, rhetoric helped to address the Iowa Department of Agriculture and Land Stewardship's concern about having little success reaching female landowners, who reported feeling excluded from traditional conservation outreach models. By focusing on the rhetorical situation at hand and promoting identification across participants, Druschke helped the Department reshape the context for conservation outreach by planning and executing a women's-only agricultural landowners meeting that provided an informative, interactive, and comfortable space for women to engage with conservation staff (Figure 3). Furthermore, in a class on the social and ecological aspects of river restoration, community interest prompted URI students to organize a miniBioBlitz, a 3-hour inventory of species along the Saugatucket River (Figure 4). By engaging elementaryschool aged children and their families in the riverine ecosystem, the students helped participants to understand and identify with the 


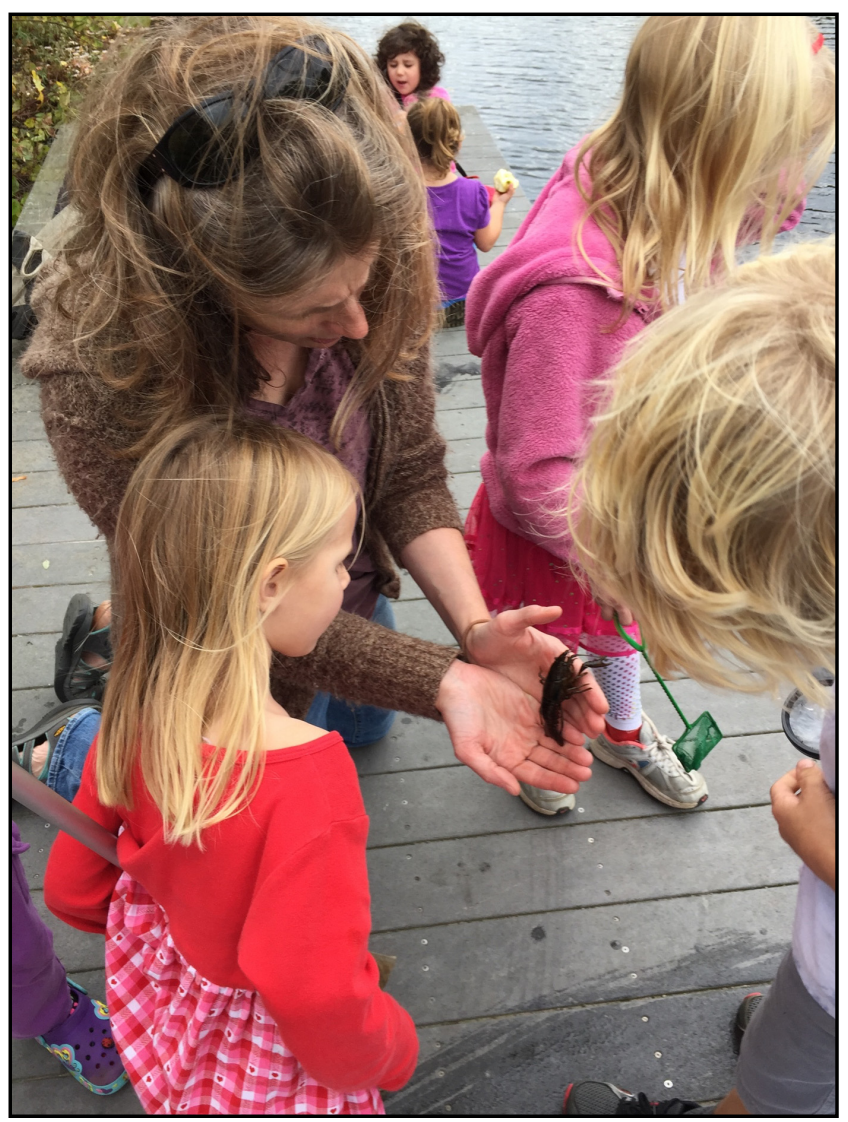

Figure 4. Dr Carol Thomber shows her daughter a one-clawed crawfish (Procambarus acutus) captured during a survey of species along the Saugatucket River in southern Rhode Island. Students in an interdisciplinary river restoration course at the University of Rhode Island organized the schoolyard BioBlitz for community participants.

degraded river and advocate on its behalf. As these examples demonstrate, a rhetorical focus can move ecologists beyond the simple transmission of information, and into consequential and relevant materials and activities that connect with audiences on their own terms.

Current science communication training does the important work of helping scientists understand and practice diverse ways of delivering their messages through storytelling, message framing, on-camera confidence, and mixed media. But rhetoric can expand the horizon of that training by focusing on how to connect with audiences to prompt identification and action, and inspire critical attention to science.

\section{Rhetoric promotes collaboration across disciplines and institutions}

The broader impacts activities discussed above exemplify the potential for rhetoric to enhance connections among individuals and improve collaborations across disciplines and institutions. From foundational theories about identification between people with different values and perspectives (Burke 1969), to contemporary work that reveals how rhetoric shapes understandings and possibilities for action within organizations (Kinsella 1999) and between humans and environments (Oravec 1984), rhetoric offers theoretical and practical starting points to help solve the pressing problems about which ecologists are most concerned. Rhetoric's potential contributions are important for the interdisciplinary efforts that are increasingly prioritized in funded research and teaching, as well as for the external collaborations essential for helping science inform societal decision making.

\section{Working across disciplines}

Interdisciplinary teams within and beyond academia are faced with the challenges posed by team members who speak different disciplinary languages and have varying views of problems and project outcomes (Miller et al. 2008; O'Rourke et al. 2014). For instance, an ecologist may define declining water quality in terms of watershed characteristics, land cover, and land use, while an economist may see the same issue in terms of the economic value of drinking water or property values contingent upon aesthetic facets of water clarity. Finding common ground between these different perspectives is important, but rhetoric reminds us that these differences never entirely disappear. Instead, the search for identification across differences - when the ecologist and economist unite to talk through but not necessarily resolve their diverse perspectives - allows interdisciplinary teams to advance their work (Burke 1969).

This insight enables researchers to work together despite competing perspectives, find points of identification between contrasting voices, translate between disciplines, address points of contention, and find productive aspects of disagreements and conflict (Druschke 2014; McGreavy et al. 2015). In one case at UMaine, researchers with the New England Sustainability Consortium, a multi-state sustainability science network focused on beach and shellfish public health and safety and decision making about dams, conducted interviews with team members to describe the range of perspectives in the project. These qualitative data helped researchers develop a conceptual framework for the project: an opportunity to identify divergent points of view and find ways to combine ideas, while still maintaining unique ways of defining problems. In another case involving eastern Iowa's Clear Creek Watershed Enhancement Project, researchers found middle ground between the concerns of agricultural landowners and conservation outreach staff in a degraded watershed, focusing on a common passion for sustained stewardship while maintaining a conversation about competing pressures on the two 
groups. In short, differences can be productive. When colleagues remain open to and share in the experience of change, they can make better decisions together.

\section{Enriching cross-disciplinary collaborations}

A rhetorical perspective promotes an improved understanding of how language shapes individuals, interpersonal relationships, and communities - including academic communities - and can enrich cross-disciplinary partnerships. This kind of critical attention to the shaping power of language can foster interactional expertise, which - unlike disciplinespecific contributory expertise - allows researchers to learn the language of another discipline in order to engage with members of a different field (Collins and Evans 2002). Rhetorical training can equip researchers with skills that not only promote more streamlined group dynamics but also foster communication with colleagues from various backgrounds. This rhetorically grounded attention to disciplinary language and interdisciplinary collaboration has allowed us to research, present, publish, and teach with colleagues in landscape, river, restoration, seed dispersal, and wildlife ecology; conservation and marine biology; environmental economics; geography; oceanography; and psychology; and with community partners hailing from diverse institutions, such as local shellfish committees, state agencies, research centers, and nonprofit organizations.

\section{Science-based decision making}

The collective potential of rhetorical training can also promote the thoughtful use of science in decision making about complex sustainability issues. Rhetoric enables members of the New England Sustainability Consortium at UMaine and URI to explore issues of power and voice across disciplines and institutions in team-based decision making. Rhetoric informs one-on-one conversations with key individuals, technical reports to the Consortium's leadership team, tailored presentations, and learning activities, such as active listening and critical reflection about interpersonal interactions. These activities are helping the Consortium identify and co-produce its research objectives in ways that attend to important factors that shape research-based relationships.

Similarly, at the US Environmental Protection Agency's Atlantic Ecology Division, rhetoric is shaping the development of an ecosystem services-based tool to help watershed organizations and state agencies prioritize wetlands restoration projects. Although the work was originally focused on identifying existing barriers and opportunities involved with restoration project implementation, interviews conducted with federal, state, municipal, and non-profit land managers offered a wider perspective on the biophysical and social contexts of aquatic restoration practice in Rhode Island, as well as the powerful arguments that sustained and altered those contexts. These findings highlight the impact of manager perspectives about communication and public engagement on ecological restoration project success (Druschke and Hychka 2015). Further, the focus on rhetoric allowed researchers to describe the distinct technical and rhetorical constraints for urban restoration projects and the on-the-ground implications of managers' language about thresholds and regime shifts in invasive species management. This research helped strengthen restoration practice in the region and provided important context for the prioritization tool. Collectively, this work highlights the important role of language as a powerful component in the wider ecosystem.

\section{Past and future connections between ecology and rhetoric}

Rhetoric clearly offers a diverse set of ideas and practices to improve science communication and sustainability-focused collaborations. This diversity shares many similarities with ecology. Like ecology, rhetoric focuses on multiple scales and seeks to understand the quality and outcomes of many different types of interactions. Like ecology, rhetoric seeks to understand the transfer of energy and information. Like ecology, it focuses on relationships, and how these dynamically change over time due to the internal and external conditions in which they occur. Meanwhile, recent discussions of rhetoric seek a more ecological approach, paying close attention to how different types of material environments like natural ecosystems, urban areas, vineyards, and more shape communication (Rickert 2013), opening up opportunities for rhetoric to learn much from ecology. In the instances where we have observed ecologists bring frogs to presentations, pick up riverbed rocks to teach students about the influence of substrate on flow, and make eelgrass necklaces to educate volunteers about restoration practices, we know ecologists have much to teach rhetoricians about communication and materiality.

Although here we have largely worked from the standpoint of what rhetoric can contribute to ecology, the sustained attention within ecology to relationships between different types of entities, complex and dynamic patterns of organization, and the formation of and changes within systems over time provide insights for this emerging discussion within rhetoric. By underscoring these theoretical and practical connections and emphasizing rhetoric's contribution to science communication, broader impacts, collaboration, and sustainability science, we hope to facilitate deeper integration between the two fields. 


\section{References}

Aristotle. 1991. On rhetoric: a theory of civic discourse. Kennedy GA (translator). Oxford, UK: Oxford University Press.

Barker S. 2006. Environmental communication in context. Front Ecol Environ 4: 328-29.

Bender JB and Wellbery DE (Eds). 1990. The ends of rhetoric: history, theory, practice. Redwood City, CA: Stanford University Press.

Bitzer LF. 1992. The rhetorical situation. Philos Rhetoric 25: 1-14.

Burke K. 1969. A rhetoric of motives. Berkeley, CA: University of California Press.

Cicero. 1968. De inventione. Cambridge, MA: Harvard University Press.

Collins HM and Evans R. 2002. The third wave of science studies: studies of expertise and experience. Soc Stud Sci 32: 235-96.

Druschke CG. 2014. With whom do we speak? Building transdisciplinary collaborations in rhetoric of science. Poroi 10: 10.

Druschke CG and Hychka KC. 2015. Manager perspectives on communication and public engagement in ecological restoration project success. Ecol Soc 20: 58.

Fahnestock J. 2013. The rhetorical arts of cooperation. J Gen Educ 62: $11-27$.

Galindo H. 2013. Getting to the "so what?" of your science. http:// compassblogs.org/blog/2013/06/20/getting-to-the-so-what-ofyour-science. Viewed 28 Aug 2015.

Gigante ME. 2015. Critical science literacy for science majors: introducing future scientists to the communicative arts. B Sci Technol Soc 34: 77-86.

Gross AG. 1994. The roles of rhetoric in the public understanding of science. Public Underst Sci 3: 3-23.

Hart DD, Bell KP, Lindenfeld LA, et al. 2015. Strengthening the role of universities in addressing sustainability challenges: the Mitchell Center for Sustainability Solutions as an institutional experiment. Ecol Soc 20: 4.

Kinsella WJ. 1999. Discourse, power, and knowledge in the management of "Big Science": the production of consensus in a nuclear fusion research laboratory. Manage Commun Q 13: $171-208$
Kuehne LM, Twardochleb LA, Fritschie KJ, et al. 2014. Practical science communication strategies for graduate students. Conserv Biol 28: 1225-35.

McGreavy B, Lindenfeld L, Bieluch KH, et al. 2015. Communication and sustainability science teams as complex systems. Ecol Soc 20: 2 .

Miller TR, Baird TD, Littlefield CM, et al. 2008. Epistemological pluralism: reorganizing interdisciplinary research. Ecol Soc 13: 46.

NSF (US National Science Foundation). 2015. National Science Foundation Research Traineeship Program. Washington, DC: NSF. www.nsf.gov/publications/pub_summ. jsp?ods_key=nsf16503. Viewed 30 Nov 2015.

Oravec C. 1984. Conservationism vs preservationism: the "public interest" in the Hetch Hetchy controversy. Q J Speech 70: 444-58.

O'Rourke MO, Crowley S, Eigenbrode SD, and Wulfhorst JD. 2014. Enhancing communication and collaboration in interdisciplinary research. Los Angeles, CA: Sage Publications.

Pace ML, Hampton SE, Limburg KE, et al. 2010. Communicating with the public: opportunities and rewards for individual ecologists. Front Ecol Environ 8: 292-98.

Rickert T. 2013. Ambient rhetoric: the attunements of rhetorical being. Pittsburgh, PA: University of Pittsburgh Press.

Scott RL. 1973. On not defining "rhetoric". Philos Rhetoric 6: $81-96$.

Shirk JL, Ballard HL, Wilderman CC, et al. 2012. Public participation in scientific research: a framework for deliberate design. Ecol Soc 17: 29

Silver S. 2003. Curing mediaphobia. Front Ecol Environ 1: 171.

Skrip MM. 2015. Crafting and evaluating Broader Impact activities: a theory-based guide for scientists. Front Ecol Environ 13: 273-79.

Wallace CS, Hand B, and Prain V. 2004. Writing and learning in the science classroom. Boston, MA: Kluwer Academic Publishers.

Whitmer AC, Ogden LA, Lawton J, et al. 2010. The engaged university: providing a platform for research that transforms society. Front Ecol Environ 8: 314-21. 